\title{
University Teachers' Attitudes Towards Distance Learning During COVID-19 Pandemic: Hurdles, Challenges, and Take-away Lessons
}

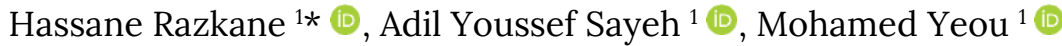

${ }^{1}$ Applied Language and Culture Studies Lab (ALCS), Chouaib Doukkali University, MOROCCO

*Corresponding Author: razkane.h@ucd.ac.ma

Citation: Razkane, H., Sayeh, A. Y., \& Yeou, M. (2022). University Teachers' Attitudes Towards Distance Learning During COVID-19 Pandemic: Hurdles, Challenges, and Take-away Lessons. European Journal of Interactive Multimedia and Education, 3(1), e02201. https://doi.org/10.30935/ejimed/11436

\begin{abstract}
The current paper discussed the challenges encountered by university teachers during online education in Morocco. It also investigated teachers' attitudes towards their distance teaching experience. 156 Chouaib Doukkali University teachers, (male $=85$ and female $=71$ ) were administered an online questionnaire via their professional email addresses. The participants, belonging to five faculties, were kindly invited to fill out the question within two weeks. For triangulation purposes, 20 (male=12 and females=8) informants were interviewed about their experience with distance education. Quantitative data were analyzed through descriptive statistics to extract demographic characteristics of the participants and provide measurements of mean values, standard deviations, and frequencies of the variables. Qualitative data were thematically analyzed. Findings showed that although the vast majority of the respondents used online teaching, many faced both technical and logistical barriers, which were reported to impede the good delivery of lessons. Also, the majority of the participants showed a negative attitude towards the COVID19 online teaching experience. The study discusses some implications for online teaching practice in tertiary education in Morocco.
\end{abstract}

Keywords: COVID-19 pandemic, higher education, distance learning, university teachers, challenges

Received: 27 Sep. $2021 \bullet$ Accepted: 9 Dec. 2021

\section{INTRODUCTION}

On March $11^{\text {th }}, 2020$, the WHO characterized COVID-19 as a global pandemic as more than 118,000 cases were identified in 114 countries, and 4,291 people lost their lives (WHO, 2020). To contain its spread among people, save lives and minimize COVID-19 impact, governments worldwide resorted to precautious measures. The lockdowns have, therefore, seriously affected educational systems. Both public and private institutions all over the globe closed and teachers were forced to adopt e-teaching. Accordingly, universities have resorted to virtual modes of delivery as an alternative to classroom classes. Different online platforms have been employed to deliver lessons. However, this abrupt decision to use distance teaching has been accompanied by several barriers and challenges.

Being a part of the global landscape, the Moroccan educational system was no exception as all institutions closed when the state declared a complete lockdown in March 2019 to minimize the rapid transmission of COVID-19 in the country. Consequently, Moroccan university teachers resorted to different online platforms as new means to deliver courses. Nevertheless, having been unprecedented, this unique experience of online teaching has been loaded with numerous obstacles.
The present paper investigated university teachers' attitudes towards distance learning during the COVID-19 pandemic. It specifically explored the main hurdles and challenges Moroccan teachers encountered during the lockdown. Identifying the key barriers teachers faced during online teaching may provide us with some pedagogical insights about what should be done to boost the productivity of online education. The paper also evaluated teachers' experience with and perception of distance learning. Understanding teachers' attitudes towards e-teaching may highlight the prospects of distance teaching/learning in tertiary education in Morocco. Based on these aims, the following research questions were formulated:

1. What were the main hurdles Moroccan university teachers encountered while delivering their online classes during the COVID-19 pandemic?

2. What are teachers' attitudes towards the online teaching experience? 


\section{LITERATURE REVIEW}

\section{Technology Acceptance Model (TAM)}

In the literature, many technology-based theoretical models have been suggested to explain users' perceptions and adoption of new information technologies. Technology Acceptance Model (TAM), developed by Davis (1989) and Bagozzi et al. (1992), is one of the prominent technology-based models suggested as an information systems theory. The model has been the most widely used theoretical framework applied to demonstrate users' acceptance and use of technology (Venkatesh \& Davis, 2000).

TAM comprises five major constructs: perceived usefulness, perceived ease of use, attitude, behavioral intention, and actual use. Davis (1989) highlights two determinant factors that influence users' decisions (not) to use new technology when introduced to them, namely perceived usefulness and perceived ease-of-use. Davis defines perceived usefulness as the extent to which individuals perceive that using a certain technology is useful and would boost their job productivity. Venkatesh and Davis (2000) maintain that once the use of a particular information system is mandatory, perceived usefulness and ease of use as determining variables to the use of technology become less significant.

The ease of use is described as "the degree to which the prospective user expects the target system to be free of effort” (Davis, 1989, p. 320). This concept is believed to influence the construct of usefulness, which is described as a user's attitudes towards the profits to be gained from the use of a certain technology. A user's perception of the ease of use of a given technology and its usefulness are two determinant factors that influence users' acceptance of a certain technology. Davis (1989) states if users of a particular technology believe it to be easy to employ and have a positive attitude towards it, they eventually adopt it.

Many empirical studies have lent support to TAM, suggesting that the model is vigorous and can be applied to investigate technology usage in diverse settings. Recent research highlights that TAM is a solid theoretical framework still relevant to investigate today's Information and Communication Technology (ICT) (Rafique et al., 2020; Sukendro et al., 2020; Yeou, 2016; Ziyad, 2016).

\section{Factors Affecting the Implementation of Distance Learning}

Primary studies on the use of ICT have reported that the implementation of such tools is highly associated with teachers' attitudes and their level of proficiency to deal with new technology (Gialamas \& Nikolopoulou, 2010). Teachers' personal barriers like technophobia and computer anxiety were also found to hinder the use of ICT in teaching (Warschauer, 2000; Ziyad, 2016). Also, lack of time, support, and resources were reported to impede the adoption of technology in teaching (Egbert et al., 2002). Thus, getting a deeper insight into teachers' level of anxiety and proficiency with technology can help ameliorate our approach to effective implementation of distance learning/teaching in tertiary education.

Many researchers have investigated the factors that affected teachers' use of e-Learning tools during the COVID-19 pandemic. Talidong \& Toquero (2021) reported that teachers face difficulties coping with technological concerns, a lack of instructional design, and other obstacles that impede emergency online education. Mansur et al. (2021), for example, found that teachers' ability to use computers was rather poor and concluded that lack of facilities hindered the integration of effective e-teaching. Similar obstacles reported to limit the implementation of e-Learning were technical and logistical problems, teachers' inability to use technology, and lack of a good learning environment and motivation (Aytac, 2021; Lestiyanawati, 2020). For example, in a study by Danchikov et al. (2021) that assessed faculty members' and students' distance learning experience during COVID-19 lockdowns, the authors classified the academic institutions into three categories: Full-distance learning, partial distance learning and traditional learning. They concluded that while the first category faced no major challenges and the second category benefited from this experience and developed their e-Learning logistics, infrastructures, and strategies, the traditional learning institutions found the implementation of e-learning challenging and costly.

Other technical problems were also reported. Amir et al. (2020), for instance, found that breaking Internet connections, the high cost of the Internet, and the difficulty to concentrate on online lessons for a long period were found to be hindrances to online education. Consistent results were found by Fatoni et al. (2020), who reported that unstable network connection, asynchronicity of instructors' voice and the lessons, inability to attend classes due to lack of access to the Internet and lack of concentration of the students were key problems that teachers had to deal while teaching online during COVID-19 pandemic. Also, research conducted by Maphosa (2021) in Zimbabwe revealed that during the COVID-19 epidemic, the problems experienced by Zimbabwean secondary school teachers in performing remote-based education were the exorbitant cost of data, a lack of adequate equipment, digital skills, and a poor choice of technology to support teaching by the government. However, while a study by Mohammadi et al. (2021) exploring the factors that affected teachers' and students' use of Higher Education Learning Management System (HELMS) in Afghanistan reported several challenges regarding e-teaching during the COVID-19 pandemic, among which are lack of policy to implement HELMS, the researchers concluded that technical issues had minor impact on the acceptance and success of HELMS.

Other obstacles reported in the literature were parents' inability to afford Internet costs, restricted Internet access, and absence of guidance to exploit e-Learning platforms (Azhari \& Fajri, 2021); and teachers' inability to effectively communicate with their students, and the difficulty to control their online behavior (Ibrohim et al., 2021).

\section{Teachers' Attitudes Towards Online Education}

Teachers' attitudes towards the online teaching experience during the COVID-19 pandemic were also examined. Sayeh and Razkane (2021) examined Moroccan high school EFL teachers' anxiety and attitudes towards Microsoft Teams on their use of the platform. The researchers found that the teachers' levels of anxiety and control of the platform played a significant role in their decision to implement such eLearning tools in their teaching. Migocka-Patrzałek et al. (2021) disclosed a strong association between prior experience with distance learning and willingness to implement this mode of teaching in the future. However, Rannastu-Avalos and Siiman (2020) found that although the majority of the teachers reported using video conferencing platforms to teach students synchronously, none of the participants conceived of the distance teaching experience as useful to collaborative learning. Sari and Nayir (2020) reported that the teachers encountered several obstacles, namely lack of constant Internet access and digital infrastructure, and disciplinary issues. Abuhammad's (2020) study identified four types of barriers students faced during online learning: 
(1) personal, (2) technical, (3) logistical, and (4) financial. These hurdles were found to negatively affect teachers' attitudes toward the e-teaching experience during the pandemic. Adov and Mäeots (2021), for instance, indicated that different internal and external obstacles hinder teachers' use of e-Learning platforms. They observed that poor infrastructure, lack of control, and lack of digital skills are the main obstacles faced by teachers. They also reported that teachers with positive attitudes towards e-Learning complain only about external obstacles, while the ones with negative attitudes pointed both internal and external factors.

Although it has some drawbacks, it seems that e-Teaching is a promising mode of delivery. From their study, Balci et al. (2021) concluded that e-learning readiness was an effective factor in the adoption of the e-Learning process. For example, Al-Anezi and Alajmi (2021) reported a high acceptance level to implement distance learning tools among English language instructors in tertiary education in Kuwait. Also, Ali (2020) investigated how teaching and learning can continue after the COVID-19 confinement. Results showed that universities worldwide were shifting towards distance learning. The study also revealed that student accessibility and motivation played a crucial role in the integration of ICT in learning. In a study conducted by Kast et al. (2021) to establish teachers' attitudes and self-efficacy beliefs during distance learning in Austria in early 2020 due to the COVID- 19 pandemic, the researchers concluded that the school system should be adjusted to fit the new situation, and teachers' need training to boost their confidence to deal with the new condition imposed by the pandemic.

It must be noted that while the above-discussed studies investigated the challenges and barriers faced by teachers in primary and secondary schools, few studies have examined the online teaching experience in tertiary education during the COVID- 19 pandemic. The current paper aimed at exploring the main hurdles university teachers faced while teaching online during the pandemic, as well as their attitudes towards this experience. It also attempted to provide some practical recommendations for post-pandemic e-Teaching practices.

\section{METHOD}

\section{Participants}

The participants were 156 Moroccan university teachers working at different faculties belonging to the University of Chouaib Doukkali in El Jadida, Morocco, namely the Faculty of Science, the Faculty of Letters and Human Sciences, the Polydisciplinary Faculty, Ecole Nationale de Commerce et de Gestion (ENCG), Ecole Nationale des Science Appliquées (ENSA), Faculté des Science Techniques (FST). 46.1 $\%$ female $(\mathrm{n}=71)$ and $53.9 \%$ male $(\mathrm{n}=83)$ were selected randomly from the population. Their age ranged between 25 and 64 years: $42.7 \%$ $(\mathrm{n}=38)$ aged between 25 to $34,32.5 \%(\mathrm{n}=50)$ between 35 to $44,29.9 \%$ $(\mathrm{n}=46)$ between 45 to 50 and $13 \%(\mathrm{n}=20)$ between 55 to 64 and they have been teaching at the aforementioned faculties from 1 to over 30 years: $48.1 \%(n=74)$ from 1 to seven years, $20.8 \%(n=32)$ from 8 to 14 , $9.1 \%(\mathrm{n}=14)$ from 15 to 21 and $15.6 \%(\mathrm{n}=24)$ from 22 to 29 and 6.5 $(\mathrm{n}=10) 30$ and over.

\section{Instruments for Data Collection}

The present paper adopted a mixed-methods approach. Both qualitative and quantitative data collection tools were utilized to evaluate university teachers' experience with online teaching during
COVID-19 lockdown. Thus, a digital questionnaire via google forms and face-to-face semi-structured interviews were used as the main data collection instruments.

The questionnaire was written in standard Arabic, since it is the participants' first language, and sent to different teachers at the aforementioned faculties via their professional email addresses. The questionnaire is divided into five sections. The first section was devoted to the collection of demographic information such as gender, age, place of work, and years of experience. Section two aimed to identify the type of platforms used to deliver lessons. The third section examined the main hurdles the participants faced before starting online teaching. Section four determined the problems the cohorts encountered while delivering their online lessons. The last section dealt with the participants' perception and evaluation of the online teaching experience. The participants were invited to fill out the questionnaire within two weeks.

Semi-structured interviews were also utilized to elicit data on the issues raised in the questionnaire for triangulation purposes. The purpose of these ethnographic interviews was to obtain in-depth data from respondents by rendering them reflect on their experience with eTeaching during the COVID-19 lockdown in Morocco to get deeper insights into the obstacles they faced and to learn how to overcome future challenges. From the same sample, twenty participants were randomly selected and sent an email requesting them to participate in the interview. After getting their approval, twenty informants, including twelve males and eight females, were contacted via mobile and invited to inform us about their e-teaching experience. The interview was also conducted in Arabic. Interviewees were asked about their computer skills, the hurdles, and challenges they faced during their online teaching, and students' attendance and interaction. Questions also focused on teachers' motives behind the adoption of certain online platforms, and evaluation of the online teaching experience. The respondents were also asked questions about how they felt while delivering their lessons and about the type of teaching they preferred.

\section{Data Analysis}

For quantitative data obtained from the questionnaire, descriptive statistics were utilized to measure the frequencies of the variables. Therefore, graphs, tables, and percentages were used to demonstrate the findings. The present study also employed thematic analysis to analyze and classify some qualitative data obtained from the interview. Thematic coding was used to identify the main hurdles and difficulties faced by Moroccan university teachers before and during their online experience, their attitudes towards distance learning experience as well.

\section{RESULTS}

\section{The Participants' Use of Online Teaching During the COVID-19 Pandemic}

The vast majority of the participants used Microsoft Teams to other e-learning platforms. $80.5 \%(\mathrm{n}=125)$ mentioned that they resorted to this platform to deliver their lessons, while 33.6\% $(n=51), 24.6 \%(n=36)$ and 22.1\% ( $\mathrm{n}=34)$ used Google Meet, Zoom, and WhatsApp, respectively. However, Moodle, YouTube, and Facebook were reported to be used only by $16.9 \%(\mathrm{n}=26), 11.7 \%(\mathrm{n}=18)$, and $11.6 \%(\mathrm{n}=17)$, respectively. $9.1 \%(n=15)$ claimed that they used other tools as Figure 1 illustrates. 


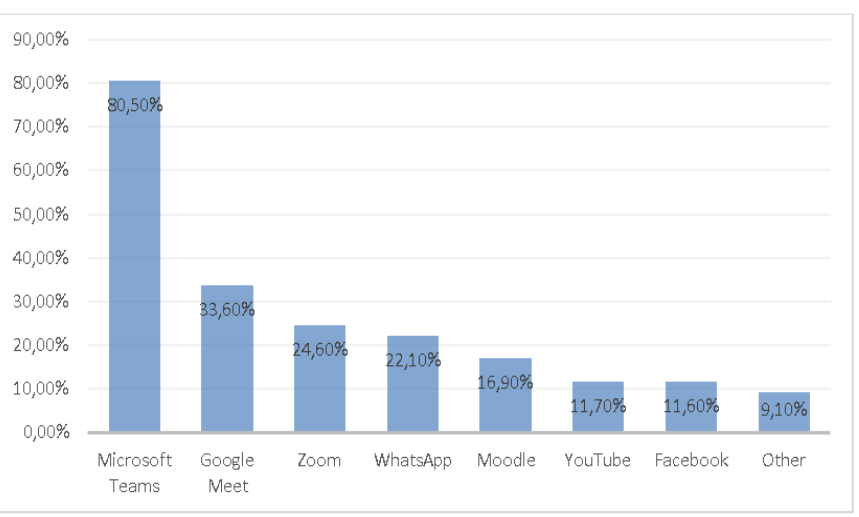

Figure 1. Frequency of using different online platforms in online teaching during COVID-19 pandemic

The Main Hurdles Encountered in Online Teaching During the COVID-19 Pandemic

To examine the main hurdles and problems Moroccan university teachers encountered while delivering their online classes during the COVID-19 pandemic, the participants were requested to identify the type of obstacles they faced in the pre-implementation phase, the difficulties they encountered while accessing the platform and when preparing digital lessons; they were also asked if they had their own computer and access to the Internet. Finally, the respondents were enquired about their motivation to deliver online courses.

According to our results, $42.6 \%(n=65)$ asserted that most of the difficulties they had before delivering online lessons were related to Internet access, while $35.9 \%(\mathrm{n}=56)$ reported encountering difficulties to access the platform and $37.2 \%(n=58)$ said they were demotivated to use teach online. Meanwhile, about a quarter of the respondents $(25.1 \%$ $(\mathrm{n}=41)$ and $25.6 \%(\mathrm{n}=40)$ respectively $)$ mentioned that most of the problems they faced were related to preparing online lessons and having their own computer (see Figure 2).

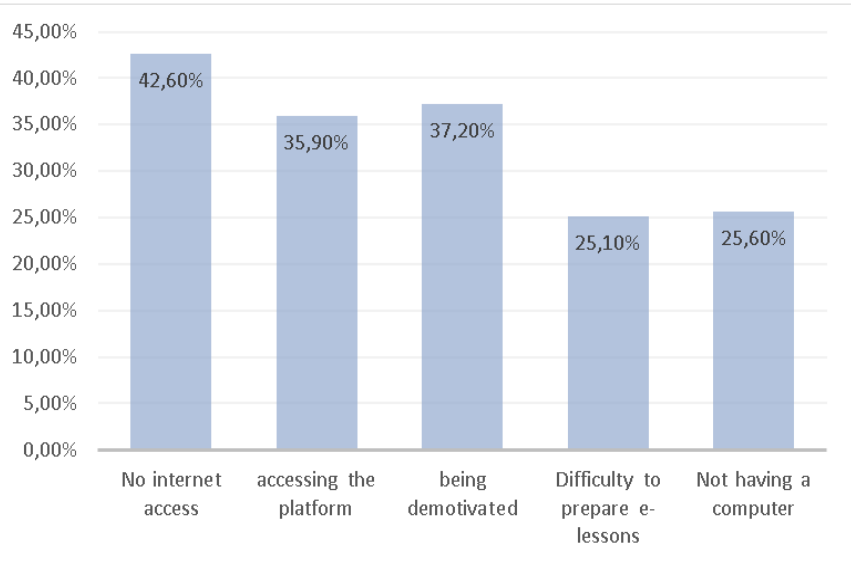

Figure 2. Hurdles faced prior to giving online courses

The interview data revealed many barriers the informants faced. Although the majority of the informants $(n=12)$ claimed that they did not face many problems before embarking on distance teaching, many $(n=8)$ said they encountered several hurdles. Six interviewees said they were unfamiliar with online platforms and did know first how to use them to deliver lessons. One of them complained, "We were not trained to use such tools"; another confessed, "I have never done this before [teaching online] and I don't know how to implement it." Also, not having access to the Internet regularly was among the issues mentioned almost by a third of our informants. However, only two respondents reported not having their own computer and said they used their mobile to interact with their students. Before they managed to teach online, about a third of the informants said they experienced some anxiety and were reluctant to try e-Teaching as it was an unprecedented experience for them. The key hindrances to the implementation of distance teaching that can be inferred from the interviewees were mainly technical, logistical, or related to lack of training to use online platforms for educational purposes.

Meanwhile, to determine the type of obstacles teachers confronted while giving their courses, the respondents were asked if they faced any difficulties concerning Internet speed, ability to use the platform well, students' disciplinary problems, lack of students' interaction, or home distractors. Most respondents $82.1 \%(\mathrm{n}=129)$ complained about the low interaction of students, and $75.6 \%(\mathrm{n}=118)$ about low Internet speed. Half of the respondents $(52.1 \%, \mathrm{n}=131)$ reported facing disciplinary issues, and $49.4 \%(n=76)$ confessed that their inability to use the platform efficiently was the main obstacle they faced. $57.1 \%(n=88)$ claimed that domestic distractors such as children and noise at home were the principal hurdles they encountered while giving online courses (see Figure 3).

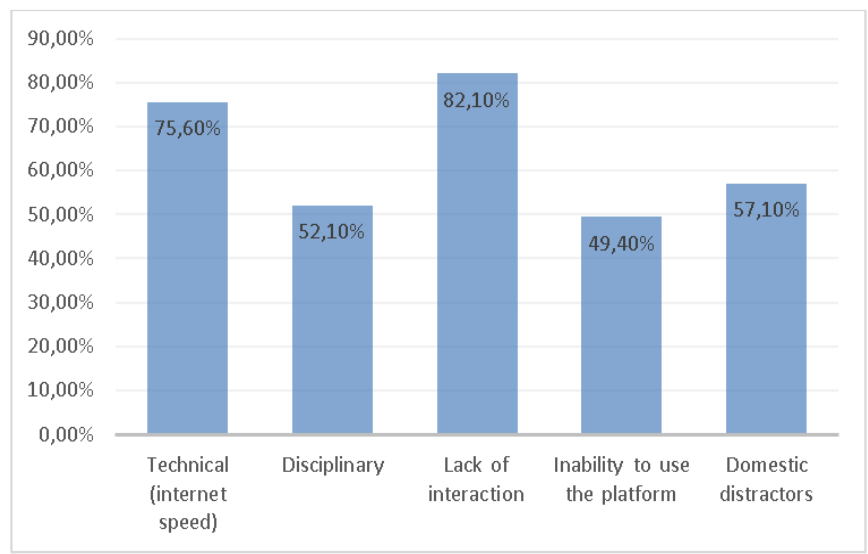

Figure 3. Problems faced while teaching

The qualitative data regarding the main hurdles the respondents confronted while delivering their online lessons is in agreement with the questionnaire results. The vast majority of the informants (18 out of 20) said they faced technical problems due to breaking Internet connections. Lack of interaction from students was another issue raised by many informants. One respondent, for example, said, "I had the impression of talking to the computer...I think that most of them just logged in to mark their presence and disappear." Another stated that "the students were reluctant to participate online." Lacking the skills to operate on the platforms was also another issue the interviewees had to deal with when they first started teaching online as one respondent explained: “At first, I didn't know what to do, but after having watched several DYI Videos on YouTube, I finally managed to use the assigned platform." However, about a quarter of the informants complained that they were not trained to teach online and had to struggle to learn the functionalities and affordances of the platforms. A final issue most respondents (12) had to deal with during online teaching was distractors. Many complained that background noise was really disturbing. Some informants admitted being interrupted by their children many times while they were delivering their lessons. Others complained that some of their students forgot or did not know how to turn off the microphone, which distracted the teaching process. 
The interviews with the informants revealed other difficulties students met during online teaching. The focal hitches students faced when trying to benefit from e-learning classes, as elicited from the respondents, were primarily linked to Internet access, technical issues, lack of necessary skills to employ the platform, and lack of interest. All the informants said their students faced technical issues due to slow Internet speed. One of the interviewees stressed that "many students don't have a computer, and the financial means to access the Internet." Another respondent explained: "The problems I encountered [while teaching online] had to do with students who did not have the equipment or Internet connection. Those students missed valuable moments of interaction and discussion." Several informants (5) asserted that some of their students were unable to use the target platform. Many informants said accessing online platforms requires good Internet access, which is impossible for students to afford regularly." One respondent maintained: "Some students didn't know how to use the platform efficiently." Another respondent asserted that "students don't have good knowledge of the functionalities of Microsoft Teams." Many informants (9) said that their students did not receive any prior training before being introduced to online classes. One female informant summed up all the challenges teachers confronted as follows: "After talking to some colleagues, I found out that we faced the same problems: Absence of interaction from students who are not used to this type of education and technical difficulties due to alternating, slow, broken Internet connection. You know, we still don't have good Internet speed in Morocco."

Participants' Perception and Evaluation of Their Online Teaching Experience

To get a deeper understanding of their attitudes toward the online teaching experience during the COVID-19 lockdown in Morocco, the respondents were asked to evaluate their online experience and the way they felt while delivering courses. Also, the respondents were requested to choose the type of teaching they prefer, whether in-person classes, online or mixed.

Our quantitative results indicated that the vast majority of the respondents were quite satisfied with their online teaching experience during the COVID-19 pandemic: $6.1 \%(\mathrm{n}=11)$ claimed that the eteaching experience was excellent; and $32.1 \%(n=50)$ and $30.8 \%(n=48)$, respectively mentioned that they found this experience to be good or not bad. However, 18.2\% $(\mathrm{n}=27)$ and $12.8 \%(\mathrm{n}=20)$ evaluated the experience as weak or fruitless as seen from Table 1.

Our interview findings are consistent with the questionnaire results. It was found that most of our informants (15 out of 20) qualified their online teaching experience as practical and useful given the circumstances. One informant explained that "at least distance learning kept students busy during the lockdown." Another interviewee said that "online platforms enabled both students and teachers to keep in touch and share concerns." However, about a quarter of the informants (7) regarded the experience as fruitless. For example, while one respondent

Table 1. Participants' preference of type of teaching

\begin{tabular}{ccc}
\hline $\begin{array}{c}\text { Teachers'evaluation of } \\
\text { online teaching experience }\end{array}$ & $\begin{array}{c}\text { Number of } \\
\text { participants }\end{array}$ & Percentage \\
\hline Excellent & 11 & $6.1 \%$ \\
\hline Good & 50 & $32.1 \%$ \\
\hline Not bad & 48 & $30.8 \%$ \\
\hline Weak & 27 & $18.2 \%$ \\
\hline Fruitless & 20 & $12.8 \%$ \\
\hline
\end{tabular}

claimed that "There is nothing better than face-to-face communication", another said that "online teaching is useless."

Overall, it can be inferred from the qualitative data that the informants considered this e-Teaching experience useful as they gained much on the personal perspective, but were rather skeptical over the realization of the goals set in the syllabus, as one informant summed it up when asked about their evaluation of the online experience: "Fruitful to me as I learned new things and new teaching strategies, but as a whole, I don't think it reached its educative goals."

We also examined the participants' level of anxiety experienced when delivering online courses. Although the vast majority of the respondents reported feeling at ease when teaching online $(2.4 \%(\mathrm{n}=5)$ said they felt very comfortable, $35.9 \%(\mathrm{n}=56)$ comfortable and $37.2 \%$ $(\mathrm{n}=58)$ neutral), while $24.5 \%$ of the respondents still experienced certain levels of anxiety while e-teaching. It was found that $19.2 \%$ $(\mathrm{n}=30)$ reported feeling nervous, and $5.3 \%(\mathrm{n}=7)$ were very nervous. Table 2 summarizes the main findings.

Table 2. Teachers' level of anxiety experienced while delivering online lessons

\begin{tabular}{ccc}
\hline How teachers felt & Number of participants & Percentage \\
\hline Very comfortable & 5 & $2.4 \%$ \\
\hline Comfortable & 56 & $35.9 \%$ \\
\hline Neutral & 58 & 37.2 \\
\hline Nervous & 30 & $19.2 \%$ \\
\hline Very nervous & 7 & $5.3 \%$ \\
\hline
\end{tabular}

The findings from the interviews align with those obtained from the quantitative data. While most of the informants (15 out of 20) reported feeling comfortable or neutral during their experience with distance teaching during the COVID-19 lockdown, about a quarter of the interviewees ( 5 out of 20) said they felt nervous when teaching online, as one confessed: "I always ask my daughter for help when I want to teach online." Another informant complained that "We aren't trained to teach online; this is all new to us." Meanwhile, others expressed a positive attitude towards this experience. One of the interviewees claimed that "It was a good experience for me because there were so many lessons that I learned from distance teaching", while another adds that "It was a new and challenging experience; at the beginning, I had problems adapting to the situation but over time I managed to use this platform in my teaching."

To elicit more data about teachers' attitudes towards distance learning, the participants were asked about the type of teaching they preferred. The results from the questionnaire showed that the vast majority of the respondents favored classroom teaching over e-teaching $(66.6 \%, n=104)$. However, only $2.9 \%(n=3)$ preferred teaching online as the only mode of delivery, while $30.5 \%(\mathrm{n}=49)$ opted for a blended teaching approach in tertiary education, as Table 3 indicates.

Table 3. Participants' preference of type of teaching

\begin{tabular}{ccc}
\hline Type of teaching preferred & Number of participants & Percentage \\
\hline In-person & 104 & $66.6 \%$ \\
\hline Online & 3 & $2.9 \%$ \\
\hline Blended & 49 & $30.5 \%$ \\
\hline
\end{tabular}

Findings obtained from the qualitative data support the quantitative results. While most of the informants were still reluctant 
to use online teaching (16 out of 20), about a few recommended opting for blended teaching. However, none of the informants preferred distance learning as the only mode of delivery in higher education. One informant asserted that "there is nothing better than face-to-face communication." Another interviewee claimed that "online teaching is useless and students don't learn anything; it is just a waste of time." In short, the vast majority of the interviewees expressed a negative attitude towards online teaching and regarded the experience as useless.

\section{DISCUSSION}

The present study explored Moroccan university teachers experience with distance learning during the COVID-19 pandemic. As stated in the introduction, it specifically examined the main hurdles teachers confronted during the distance teaching process. A final aim was to find out teachers' perception and evaluation of e-Teaching in tertiary education. The results revealed that although the vast majority of the participants delivered online lessons through different platforms, many reported facing logistical, technical, and disciplinary issues as well as problems linked to students' lack of interaction and internal distractors. The results of the current study are supported by other researchers who reported that technical and logistic problems (Aytac, 2021; Lestiyanawati, 2020), lack of constant Internet access and digital infrastructure (Sari \& Nayir, 2020), and Internet costs, restricted Internet access, and absence of guidance to exploit e-Learning platforms (Azhari \& Fajri, 2021) are among the major factors affecting teachers' use of e-Learning tools. It was also found that although most of the participants had a positive attitude towards e-Teaching and qualified the experience as good, many exhibited a reluctance to use e-Teaching and regarded the experience as fruitless.

The Participants' Use of Online Teaching During the COVID-19 Pandemic

The study revealed that university teachers in Morocco faced different difficulties with online teaching. The switch to this mode of delivery was abrupt and neither teachers nor students were prepared for it. This factor may be responsible for the challenges faced by these teachers. Another possible explanation for this finding is lack of training. That is, teachers had no formal training on how to teach using these platforms and this resulted in a lack of familiarity and hurdles for some to deliver their lessons using such tools. This experience identified different challenges and barriers that can be set as a reference point for the implementation of remote learning in the future.

As indicated by Venkatesh and Davis (2000), once a particular technology is mandatory, perceived usefulness and ease of use become less-determining factors in using that technology. Results of the current research showed that the vast majority used Microsoft Teams as it was the official online platform adopted by the Ministry of Education. The choice of that platform was rather mandatory and only a few respondents opted for other platforms for their easiness of use or usefulness. Still, as the results of the study indicated, teachers reported difficulties dealing with various platforms. Henceforth, the familiarization of teachers with such e-learning platforms would raise their tendency to use them more. This aligns with Kast et al. (2021), who affirm that teachers' training on technology positively affects their attitudes towards implementing e-Learning tools, and MigockaPatrzałek et al. (2021) who found a strong association between prior experience with distance learning and willingness to implement this mode of teaching in the future.

The Main Hurdles Encountered in Online Teaching During the COVID-19 Pandemic

In concordance with Adov and Mäeots (2021), the current study found that other problems pointed out by the respondents were related to logistics and technical matters. Both external and internal obstacles were reported by the respondents. Teachers and faculties used different platforms with varying degrees and some students could not attend the online classes due to lack of Internet access and equipment. One explanation for the technical problems reported by the participants could be attributed to low internet speed and constant connection failure. The results also point to the likelihood that many students cannot afford Internet access regularly because the cost of the Internet is still high in Morocco. Our findings are also in line with those of Abuhammad's (2020), Amir et al.'s (2020), Fatoni et al.'s (2020), Azhari and Fajri (2021), Sari and Nayir's (2020), and Ibrohim et al. (2021) who reported that the major challenges faced by teachers and students alike were related to technical problems, such as Internet access, logistics, such as lack of material, and other problems related to disciplinary issues.

\section{Participants' Perception and Evaluation of Their Online} Teaching Experience

The last aspect investigated by this study was teachers' perception and evaluation of their e-Teaching experience during the COVID-19 lockdown. While the vast majority still opted for in-person classes and asserted that the experience did not reach the underlined goals set by the Ministry of Education, some teachers perceived the experience as being fruitful at the personal level. In contrast to Rannastu-Avalos and Siiman (2020), who found none of the participants in their study conceived of the distance teaching experience as useful to collaborative learning, the findings of the current study revealed that most of the respondents claimed that they gained a lot from this experience. It appears that teachers' efforts to deliver online lessons to their students pushed them to learn how to use online platforms. This is consistent with Davis (1989), who claimed that when users of a certain technology perceive it as useful, they are very likely to have positive attitudes towards it and thus apply it.

However, a significant number of the participants showed a negative attitude towards e-Teaching and exhibited high levels of anxiety. As proposed by Sayeh and Razkane (2021), Warschauer (2000), and Ziyad (2016) lowering teachers' anxiety towards the use of eLearning tools would result in high potential implementation of these tools in their teaching. Our findings also suggested that one of the factors behind this negative attitude was the difficulty to use online platforms. According to Davis (1989), the easiness to use a particular technology also plays a determining factor in its adoption. Moreover, other studies reported that teachers' ability to use technology affected its integration into their teaching process (Mansur et al., 2021) and that the level of proficiency to deal with new technology is highly associated with teachers' attitudes towards that particular technology. Thus, lowering teachers' levels of anxiety towards the use of e-Learning tools can be achieved through constant use of and training on these tools to boost teachers' proficiency on the use of technology.

It appears that further training on ICT use and integration of elearning as an integral part of the curricula would play a salient role in 
raising teachers' acceptance and use of online platforms as new modes of delivery, which can enhance interaction and cooperation among both teachers and students in tertiary education. Perceived usefulness and perceived ease of use of a certain technology are still determining factors in making teachers adopt a given technology for educative purposes. That is, the teachers, for example, who find it difficult to use particular online platforms when trying to deliver their lessons, have a negative attitude towards distance teaching, and thus are demotivated to exploit these tools in teaching. Also, platforms that are user-friendly and have easy-to-use functionalities would encourage some teachers to favor them over others.

\section{CONCLUSIONS AND IMPLICATIONS}

The current study evaluated Moroccan university teachers' online teaching experience during the COVID-19 pandemic. It specifically investigated the types of hurdles the participants faced while delivering online lessons as well as their attitudes towards this experience. As mentioned earlier, although the majority used online platforms as new modes of delivery, many encountered several barriers: Technical, logistical, professional, disciplinary, and personal. Also, our study found that although many teachers, especially those who were not familiar with using technology in teaching and who experienced anxiety, held a negative attitude towards the outcome of the experience, many perceived the experience as enriching and instructive.

Also, the fact that teachers and faculties used different platforms with varying degrees shows that there is an absence of a common and unifying strategy to teach online in tertiary education. One way to encourage the use of ICT in teaching at university is to provide the necessary logistics and good training to teachers to cope with this new mode of teaching. We suggest that ICT courses and e-learning classes should be integral components of the curriculum and equipment and Internet connection should be available on-campus to boost teachers' and students' confidence and familiarity with such tools and consequently raise their level of use and implementation.

The COVID-19 pandemic was a turning point in the world and has demonstrated that the system of education should be reconsidered. The world is changing very fast, and now technology becomes a must in the process of evolution. Implementing such tools in delivering lessons as an integral part of the curriculum would raise teachers' and students' familiarity and acceptance to use them. Future research should focus on the outcomes of distance learning as the only mode of delivery to examine the prospects of the virtual teaching/learning process.

Author contributions: All authors were involved in concept, design collection of data, interpretation, writing, and critically revising the article. All authors approve final version of the article.

Funding: The authors received no financial support for the research and/or authorship of this article.

Declaration of interest: Authors declare no competing interest.

Data availability: Data generated or analysed during this study are available from the authors on request.

\section{REFERENCES}

Abuhammad, S. (2020). Barriers to distance learning during the COVID-19 outbreak: A qualitative review from parents' perspective. Heliyon, 6(11), e05482. https://doi.org/10.1016/ j.heliyon.2020.e05482

Adov, L., \& Mäeots, M. (2021). What can we learn about science teachers' technology use during the COVID-19 pandemic? Education Sciences, 11(6), 255. https://doi.org/10.3390/ educsci1 1060255

Al-Anezi, Y. H., \& Alajmi, S. M. (2021). Factors that influence English teachers' acceptance and use of e-learning technologies. International Education Studies, 14(9), 15-27. https://doi.org/ 10.5539/ies.v14n9p15

Ali, W. (2020). Online and remote learning in higher education institutes: A necessity in light of COVID-19 pandemic. Higher Education Studies, 10(3), 16-25. https://doi.org/10.5539/ hes.v10n3p16

Amir, L. R., Tanti, I., Maharani, D. A., Wimardhani, Y. S., Julia, V., Sulijaya, B., \& Puspitawati, R. (2020). Student perspective of classroom and distance learning during COVID-19 pandemic in the undergraduate dental study program Universitas Indonesia. BMC Medical Education, 20(1), 1-8. https://doi.org/10.1186/s12909-02002312-0

Aytac, T. (2021). The problems faced by teachers in Turkey during the COVID-19 pandemic and their opinions. International Journal of Progressive Education, 17(1), 2021. https://doi.org/10.29329/ ijpe.2020.329.26

Azhari, B., \& Fajri, I. (2021). Distance learning during the COVID-19 pandemic: School closure in Indonesia. International Journal of Mathematical Education in Science and Technology, 1-21. https://doi.org/10.1080/0020739X.2021.1875072

Bagozzi, R. P., Davis, Fre, D. D., \& Warshaw, P. R. (1992). Development and test of a theory of technological learning and usage. Human Relations, 45(7), 659-686. https://doi.org/10.1177/ 001872679204500702

Balci, T., Temiz, C. N., \& Sivrikaya, A. H. (2021). Transition to distance education in COVID-19 period: Turkish pre-service teachers' elearning attitudes and readiness levels. Journal of Educational Issues, 7(1), 296. https://doi.org/10.5296/jei.v7i1.18508

Danchikov, E. A., Prodanova, N. A., Kovalenko, Y. N., \& Bondarenko, T. G. (2021). Using different approaches to organizing distance learning during the COVID-19 pandemic: Opportunities and disadvantages. Linguistics and Culture Review, 5(S1), 587-595. https://doi.org/10.37028/lingcure.v5nS1.1444

Davis, F. D. (1989). Perceived usefulness, perceived ease of use, and user acceptance of information technology. MIS Quarterly, 13(3), 319339. https://doi.org/10.2307/249008

Egbert, J., Paulus, T. M., \& Nakamichi, Y. (2002). The impact of call instruction on classroom computer use: A foundation for rethinking technology in teacher education. Language Learning and Technology, 6(3), 108-126. 
Fatoni, Arifiati, N., Nurkhayati, E., Nurdiawati, E., Fidziah, Pamungkas, G., Adha, S., Irawan, Purwanto, A., Julyanto, O., \& Azizi, E. (2020). University students online learning system during COVID-19 pandemic: Advantages, constraints and solutions, Systematic Reviews in Pharmacy, 11(7), 570-576.

Gialamas, V., \& Nikolopoulou, K. (2010). In-service and pre-service early childhood teachers' views and intentions about ICT use in early childhood settings: A comparative study. Computers and Education, 55(1), 333-341. https://doi.org/10.29329/ijpe.2020. 329.26

Ibrohim, Sudrajat, A. K., \& Saefi, M. (2021). Assessing Indonesian teacher's perspective on the implementation of distance learning due to COVID-19 based on online survey. Journal of Turkish Science Education, 18(COVID-19 Special Issue), 46-59.

Kast, J., Lindner, K. T., Gutschik, A., \& Schwab, S. (2021). Austrian teachers' attitudes and self-efficacy beliefs regarding at-risk students during home learning due to COVID-19. European Journal of Special Needs Education, 36(1), 114-126. https://doi.org/10.1080/08856257. 2021.1872849

Lestiyanawati, R. (2020). The strategies and problems faced by Indonesian teachers in conducting e-learning during COVID-19 outbreak. CLLiENT (Culture, Literature, Linguistics, and English Teaching), 2(1), 71-82. https://doi.org/10.32699/cllient.v2i1.1271

Liu, M., Moore, Z., Graham, L., \& Lee, S. (2002). A look at the research on computer-based technology use in second language learning: Review of literature from 1990-2000. Journal of Research on Technology in Education, 34(3), 250-273. https://doi.org/10.1080/ 15391523.2002.10782348

Macaruso, P., \& Rodman, A. (2011). Benefits of computer-assisted instruction to support reading acquisition in English language learners. Bilingual Research Journal, 34(3), 301-315. https://doi.org/10.1080/15235882.2011.622829

Mansur, H., Jumadi, Mastur, Utama, A. H., \& Prastitasari, H. (2021). The problem of distance learning during the COVID-19 pandemic. Ilkogretim Online [Elementary Education Online], 20(4), 168-175.

Maphosa, V. (2021). Teachers' perspectives on remote-based teaching and learning in the COVID-19 era: Rethinking technology availability and suitability in Zimbabwe. European Journal of Interactive Multimedia and Education, 2(1), e02105. https://doi.org/10.30935/ejimed/9684

Migocka-Patrzałek, M., Dubińska-Magiera, M., Krysiński, D., \& Nowicki, S. (2021). The attitude of the academic community towards distance learning: A lesson from a national lockdown. The Electronic Journal of E-Learning, 19(4), 262-281. https://doi.org/10.34190/ejel.19.4.2405

Mohammadi, M. K., Mohibbi, A. A., \& Hedayati, M. H. (2021). Investigating the challenges and factors influencing the use of the learning management system during the COVID-19 pandemic in Afghanistan. Education and Information Technologies, 26, 5165-5198. https://doi.org/10.1007/s10639-021-10517-z

Muir-Herzig, R. G. (2004). Technology and its impact in the classroom. Computers and Education, 42(2), 111-131. https://doi.org/10.1016/ S0360-1315(03)00067-8
Rafique, H., Almagrabi, A. O., Shamim, A., Anwar, F., \& Bashir, A. K. (2020). Investigating the acceptance of mobile library applications with an extended technology acceptance model (TAM). Computers and Education, 145, 103732. https://doi.org/10.1016/j.compedu. 2019.103732

Rannastu-Avalos, M., \& Siiman, L. A. (2020). Challenges for distance learning and online collaboration in the time of COVID-19: Interviews with science teachers. In A. Nolte, C. Alvarez, R. Hishiyama, I. A. Chounta, M. Rodríguez-Triana, \& T. Inoue T (Eds.), Collaboration technologies and social computing. CollabTech 2020 (pp. 128-142). Springer, Cham. https://doi.org/10.1007/978-3030-58157-2_9

Sari, T., \& Nayir, F. (2020). Challenges in distance education during the (Covid-19) pandemic period. Qualitative Research in Education, 9(3), 328-360. https://doi.org/10.17583/QRE.2020.5872

Sayeh, A. Y., \& Razkane, H. (2021). Moroccan high school EFL teachers' attitudes and anxiety on using Microsoft Teams platform. TESOL and Technology Studies, 2(2), 29-40. https://doi.org/10.48185/ tts.v2i2.267

Sukendro, S., Habibi, A., Khaeruddin, K., Indrayana, B., Syahruddin, S., Makadada, F. A., \& Hakim, H. (2020). Using an extended Technology Acceptance Model to understand students' use of elearning during COVID-19: Indonesian sport science education context. Heliyon, 6(11), e05410. https://doi.org/10.1016/ j.heliyon.2020.e05410

Talidong, K. J. B., \& Toquero, C. M. D. (2021). Facing COVID-19 through emergency online education anchored in Khan's framework: Case of Philippine teachers in Xi'an, China. European Journal of Interactive Multimedia and Education, 2(1), e02104. https://doi.org/10.30935/ejimed/9683

Venkatesh, V., \& Davis, F. (2000). A theoretical extension of the technology acceptance model: Four longitudinal field studies. Management Science, 46(2), 186-204. https://doi.org/10.1287/ mnsc.46.2.186.11926

Warschauer, M. (2000). Technology and school reform: A view from both sides of the tracks. Education Policy Analysis Archives, 8, 4. https://doi.org/10.14507/epaa.v8n4.2000

Warschauer, M. (2000a). Online learning in second language classrooms. In M. Warschauer \& R. Kern (Eds.), Network-based language teaching: Concepts and practice (pp. 41-58). Cambridge UniversityPress.https://doi.org/10.1017/CBO9781139524735.005

World Health Organization. (2020). https://www.euro.who.int/en/ health-topics/health-emergencies/coronavirus-covid-19/novelcoronavirus-2019-ncov

Yeou, M. (2016). An investigation of students' acceptance of Moodle in a blended learning setting using technology acceptance model. Journal of Educational Technology Systems, 44(3), 300-318. https://doi.org/10.1177/0047239515618464

Ziyad, H. (2016). Technology-mediated ELT writing: Acceptance and engagement in an online Moodle course. Contemporary Educational Technology, 7(4), 314-330. https://doi.org/10.30935/cedtech/6179 